\title{
Applying systems thinking and aligning it to systems engineering
}

\author{
Joseph Kasser \\ The Right Requirement Ltd \\ 50 Crane Way \\ Cranfield, MK43 OHH \\ England
}

\author{
Tim Mackley \\ Building 83 \\ Cranfield University \\ Cranfield, MK43 0AL \\ England
}

Copyright @ 2008 by Joseph E. Kasser. Used by INCOSE with permission for the INCOSE 2008 Symposium.

\begin{abstract}
This is a paper on thinking about thinking. Systems engineering is an emerging discipline in the area of defining and solving problems in the manner of (Wymore, 1993). The emerging paradigm for problem solving is "systems thinking". Both systems engineering and systems thinking have recognized the need to view a system from more than one perspective. This paper proposes a set of perspectives for applying systems thinking in systems engineering and then defines a systems thinking perspective set of views for a system, the use of which will provide one way of aligning systems thinking to systems engineering. The paper then provides an example of applying the set of perspectives to the Royal Air Force Battle of Britain Air Defence System and shows that not only does the set of perspectives provide a way to model the system; it also picked up two potentially fatal flaws in the system. The paper then concludes with some observations on the state of systems engineering from a number of the perspectives.
\end{abstract}

\section{The need for systems thinking}

The need for systems thinking is widely recognized at this time. Figuring out how to meet the need and actually apply systems thinking in a systemic and systematic manner constitutes a problem yet to be solved. (Khisty and Mohammadi, 2001) page 22) quote Ackoff (1986)'s suggestion that there are at least four ways of treating problems. These are:

1. Absolving the problem.

2. Resolving the problem.

3. Optimizing the solution.

4. Dissolving the problem.

Absolving the problem is traditionally known as "ostrich management". This approach ignores the problem or imagines that it will eventually disappear on its own.

Resolving the problem is a traditional systems engineering approach to removing or suppressing the problem. This approach takes appropriate action based on experience, common sense and expertise.

Optimizing the solution is another traditional systems engineering approach based on working out an outcome through experimentation or analysis.

Dissolving the problem. This approach redesigns the system containing the problem or changes the perspective from which the problem is viewed to produce an innovative solution.

\footnotetext{
${ }^{1}$ The research underlying this paper was funded by a grant from The Leverhulme Trust to Cranfield University.
} 
This approach generally requires systems thinking. And, as systems thinking is emerging both as a school of management thought and an academic discipline, the ability to perform systems thinking is a critical competency for a systems engineer.

The research that is described in the remainder of this paper takes this fourth approach.

\section{Applying systems thinking}

The literature abounds with:

1. publications advocating the use of systems thinking, e.g. (Flood and Jackson, 1991),

2. publications describing how an understanding of the way things are connected together provides one with a competitive advantage over those who do not share the same understanding ${ }^{2}$ (Morgan, 1997).

3. philosophical and academic theories of systems thinking, e.g. (Flood and Jackson, 1991), and

4. the need to view problems from various perspectives, e.g. (Morgan, 1997).

However, the literature on how to actually apply systems thinking to get something seems to be mostly limited to advice advocating the use of causal loops, non-linear thinking, and the recognition that systems exhibit behaviour that may be cyclic. This is a critical gap in systems engineering. In addition, if a practical application of systems thinking to be developed can also be aligned with systems engineering, and then applied in the workplace, the practice of systems engineering should undergo a marked improvement because the application of systems thinking, namely much of systems engineering would become " $a$ philosophy and $a$ way of life" (Hitchins, 1998). This paper tackles the issue of applying systems thinking, filling that gap in systems engineering. It does this by using a modified version of the streams of systems thinking (Richmond, 1993) and further proposes an alignment of systems thinking with systems engineering to build systems thinking into the systems engineering process by definition.

Traditional systems engineering has focused on analysis which has three steps (Ackoff, 1991). This is reductionism - reducing the parts to ever decreasing components. Systems thinking on the other hand also has three steps but they are slightly different (Ackoff, 1991). Comparing the two sets of steps in the manner shown in Table 1, one can see that the focus of analysis or reductionism is to look inwards while the focus of systems thinking is to look outwards. Both have their place in developing an understanding of a system (Hitchins, 1992) page 14).

Table 1 Analysis and Systems Thinking

\begin{tabular}{|c|c|}
\hline Analysis (Machine Age) & Systems Thinking (Systems Age) \\
\hline 1. Take apart the thing to be understood & $\begin{array}{l}\text { 1. A thing to be understood is conceptualized } \\
\text { as a part of one or more larger wholes, not } \\
\text { as a whole to be taken apart; }\end{array}$ \\
\hline 2. Try to understand how these parts worked & $\begin{array}{l}\text { 2. An understanding of the larger system is } \\
\text { sought; }\end{array}$ \\
\hline $\begin{array}{l}\text { 3. Assemble an understanding of the parts into } \\
\text { an understanding of the whole. }\end{array}$ & $\begin{array}{l}\text { 3. The system to be understood is explained } \\
\text { in terms of its role or function in the } \\
\text { containing system. }\end{array}$ \\
\hline
\end{tabular}

The application of systems thinking in the literature is generic with references to

\footnotetext{
${ }^{2}$ The earliest description found in the literature was in Luzzatto, M.C., The Way of God, about 1735.
} 
understanding relationships, casual loops, but does not seem to be organized in a consistent manner ${ }^{3}$. However, one organized approach to applying systems thinking discovered in the literature was by (Richmond, 1993) who introduced seven streams of system thinking. Richmond used a reductionist approach on systems thinking to allow it to be applied holistically to real world. The research behind this paper has developed a similar set of streams or viewpoints called System Thinking Perspectives (STP). The STPs can provide a competitive edge since "people who learn to read situations from different (theoretical) points of view have an advantage over those committed to a fixed position. For they are better able to recognize the limitations of a given perspective. They can see how situations and problems can be framed and reframed in different ways, allowing new kinds of solutions to emerge" (Morgan, 1997).

\section{The System Thinking Perspectives}

Systems engineers are used to viewing systems through sets of models or views such as (Hately and Pirbhai, 1987) or the (DoDAF, 2004) each of which examines a situation from a number of points of view. This paper makes use of that concept and describes a set of STPs along the lines of (Richmond, 1993) to be used in conjunction with both developing an understanding of a system and organizing its representation. These perspectives are:

1. Operational

2. Functional

3. Big picture

4. Structural

5. Generic

6. Continuum

7. Temporal

8. Quantitative

9. Scientific

The first eight perspectives are descriptive, while the scientific perspective is prescriptive. Consider each perspective in turn.

Operational perspective. The operational perspective is the manner in which the system operates or will operate (in the case of a new system). The system is viewed as a black box. The perspective shows the inputs and outputs and their relationships. This corresponds to the traditional 'open system' view. The black box perspective abstracts out (filters) the details of the internal nature of the system providing a view of the forest rather than the individual trees. The perspective is documented in the form of Use Cases, concept of operations, and other appropriate formats and is used when producing operational requirements.

Functional perspective. The functional perspective describes the functions or activities performed by the system without reference to which of the elements of the system perform those functions. This corresponds to the traditional 'closed system' view and includes the cause and effect feedback loops. The system is viewed as a white box. Depending on the level of system decomposition, this can be a view of what is being done or how it is being done. This perspective is used when producing functional requirements.

\footnotetext{
${ }^{3}$ Another characteristic of an emerging discipline.
} 
Big picture perspective. The big picture perspective provides a view of the forest rather than the trees. It views the system within the context of its containing system - its environment, the closely coupled adjacent systems with which it interacts and any loosely coupled more distant

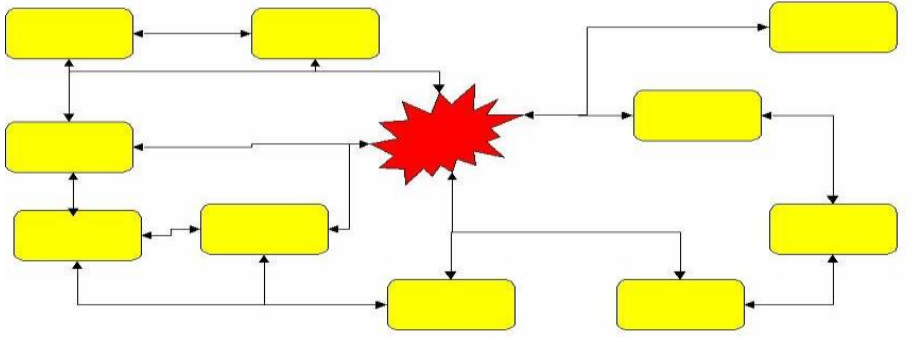

Figure 1 The big picture - system of interest and adjacent systems systems as shown in Figure 1 (Kasser, 2001). Thus the perspective contains information about the external boundary of the system and the assumptions behind the location of the boundary.

Structural perspective. The structural perspective views the systems' architecture and the internal subsystem partition boundaries and any effects on the system due to its internal structure. This perspective incorporates the traditional physical, technical and architectural framework views.

Generic perspective. The generic perspective looks for similarities between the system and other systems in the same or other domains, in the present or in the past. This perspective leads to the:

- Inheritance of domain requirements from similar systems in Area 2B of the HKM framework (Kasser, 2007a, c).

- Adoption of lessons learned from other projects and determination if those lessons are applicable to current project.

- Innovative design approaches in the system domain using approaches from other domains. It is probable that someone else in another domain has already faced and solved the problem currently being faced (Barry, et al., 2007). For example, one of the factors leading to the successful architecture of the LuZ Solar Electrical Generating System in the early 1980's (Kasser, 2007b) was the insight that generically the network of microprocessor controlled local controllers on the mirrors and a central station was similar to a constellation of satellites and their central control station.

Continuum perspective. The continuum perspective recognizes that:

- Things are not necessarily 'either-or', there may be states in between. This leads to concepts such as 'fail soft' in operation and the replacement of 'either-or' questions such as "is systems engineering an undergraduate or a postgraduate subject?" by questions in the form of "to what degree is systems engineering a postgraduate subject?" or "what is the knowledge needed by a systems engineering engineer and how much of it can be taught as an undergraduate subject?" This is a very different perspective to the traditional 'either-or' 'one right way' perspective.

- Changing conditions may cause movement along the continuum. This leads to the insight that systems can exhibit different types of behaviour in different situations rather than always behave in the same way and that the transition conditions causing that change in behaviour may not be known. In the case of human systems, the continuum perspective points out that: 
1. Maslow's hierarchy (Maslow, 1970) may not be so much as a pyramid, but a pie, and motivating people becomes a matter of figuring out which slices of the pie to offer them (Kasser, 1995).

2. Theory X and Theory Y (McGregor, 1960) behaviour may be two ends of a situational continuum of behaviour rather than two opposing behaviour patterns.

The 'fail soft' perspective leads to an analysis of failure modes for the system and each of its components. The analysis may influence the structural and functional perspectives in the design of the system. The perspective also leads to a risk analysis of the probability and effect of internal and externally induced failures and ways to mitigate the failures. Internal failures are failures of components due to aging and normal wear and tear (Moubray, 2005), external failures are those inflicted from without, such as natural disasters, sabotage and enemy action.

Temporal perspective. The temporal perspective looks at how the system behaves over time. If the system exists, past patterns of behaviour are examined and future patters are predicted using this perspective. Insights from this perspective include:

- The consideration of Availability, maintenance, logistics, obsolescence, etc.

- The concept of prevention.

- The need to consider the effects due to aging, the need for upgrades and replacement and the effect of diminishing sources of materiel such as spare parts for the technology to be used in the system.

- Lessons to be learned from the system implementation and improvements for future iterations of the system.

- An understanding that even if the implemented solution works it may introduce further problems that only show up after some period of time. These time delays were grouped (Kasser, 2002) as:

- First order - noticeable effect within a second or less.

- Second order - noticeable effect within a minute or less.

- Third order - noticeable effect within an hour or less.

- Fourth order - noticeable effect within a day or less.

- Fifth order - noticeable effect within a week or less.

- Sixth order - noticeable effect within a month or less.

- Seventh order - noticeable effect within a year or less.

- Eighth order - noticeable effect within a decade or less.

- Ninth order - noticeable effect within a century or less.

o Tenth order - noticeable effect after a century or more.

This is the perspective in which temporal cause and effect loops are considered and the reflection on the past provides lessons learned from the system. This perspective also alerts analysts that past performance may not be a useful predictor of future performance unless the factors contributing to the past performance are understood.

Quantitative perspective. The quantitative perspective relates to the big picture and to the operational and functional perspectives to develop the performance requirements. According to (Richmond, 1993), the quantitative perspective however is not about the need to measure everything, "it is more the recognition that numbers must be useful, not necessarily perfect and need not be absolute". Sometimes relative comparisons are more useful. This perspective is about quantification rather than measurement, and helps to understand relationships and leads to the mathematical relationships in (functional) models and simulations. An example of quantification is the Likert scale, named after its originator Rensis Likert (1903-1981). The 
Likert scale offers a means of determining attitudes across a continuum of choices, such as "strongly agree," "agree", "don't care", "disagree" and "strongly disagree." A numerical value can then be allocated to each statement for further analysis. The numerical values may not necessarily be in a linear relationship.

Scientific perspective. Whereas the other descriptive perspectives are used to examine (and document) a system, problem or situation, this prescriptive perspective covers the formulation and testing of hypothetical candidate representations of the system to meet the need that will be constructed in the design and implementation phases of the system development life cycle (SDLC), and the construction of the tests used to validate the representation by the Test and Evaluation (T\&E) function of systems engineering. The scientific perspective forms the basis for the 'trial and error' approach to problem solving.

\section{Using the systems thinking perspectives}

The application of each of the descriptive STPs begins by asking the questions "who, what, where, when, why and how" (Kipling, 1912). However, since the boundaries of the STPs are artificial for the benefit of applying systems thinking, the understanding gained from one of the STPs might generate a scientific perspective (hypothesis or solution) documented in a different STP or even a mixture as demonstrated by the following examples:

1. The HKM Framework (Kasser, 2007a, c) is a hypothesis (scientific STP) presenting the concept using a structural STP, yet the insight to postulate it came from the big picture STP (vertical axis), the temporal STP (horizontal axis) and the continuum STP (for the problem solving dimension).

2. Figure 3 (Kasser, 2001) depicts the parallel evolution of the systems in the big picture STP shown in Figure 1. The colours in the figure emphasize that each of the systems may be in different stages of their in-service operate and upgrade part of the SDLC. This is a temporal big picture STP and provides insight on the need to consider the effects of evolution of adjacent systems on the system of interest. This insight was applied in about 1992 in the NASA Goddard Space Flight Center Systems Engineering and Support Contract when Code 560 was faced with a major problem. When the manufacturer of the

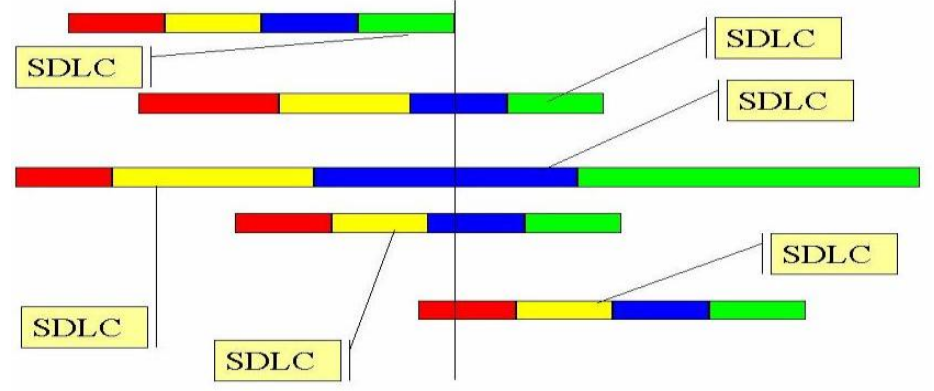

Figure 2 Parallel evolution minicomputer used in their Packet Data Processing facility announced that they would no longer be supporting the minicomputer, Code 560 realized that they had a major risk in that the then current architecture would probably not be able to support the operational spacecraft due to the aging of equipment and the lack of spare parts to repair expected failures. This is a problem being faced by many current systems in the Defence environment. In this instance, this insight resulted in an out-of-the box solution to the problem not only provided the needed support but also saved NASA $\$ 1,500,000$ (Kasser, 2006). 


\section{An example of the application of the STPs}

Having discussed a way of applying systems thinking to systems engineering via the STPs, the methodology for applying the STPs is to make use of the template shown in Table 2 until they become intuitive. For each perspective, ask the appropriate Kipling question. If nothing comes to mind, skip to the next question. The template is a starting point for discussion and documentation.

The paper now demonstrates the application of the STPs by aligning views of a system to the STPs. The example system under consideration is the Royal Air Force (RAF) Battle of Britain Air Defence System (RAFBADS) which was used to foil the Luftwaffe's attempt to gain control of the sky over southern England in 1940. The RAFBADS was designed in the late 1930's and deployed in time to meet the Luftwaffe threat. Travel back in time to the period in which the RAFBADS was being designed and view the problem of providing an air defence system from the STPs. However, the following discussion is not intended to be a complete application of the STPs to the problem of providing an air defence system. Rather, the discussion highlights aspects brought out by the STPs.

Operational STP. The system inputs are pilots, aircraft, ordnance, fuel, and mains generated electrical power. The system outputs (the products it produces) are damaged and destroyed enemy aircraft. The feedback function or relationship between outputs and inputs is that pilots and aircraft lost to enemy action, ordnance and fuel consumed must be replaced. From a self-regulating perspective the system strives to maintain a steady state in terms of operational aircraft (the combination of mission-ready aircraft and trained pilots).

The purpose of the RAFBADS is defence; it will be a reactive system responding to stimuli. A set of detailed operational scenarios would be developed to describe anticipated responses to specific enemy threats in terms of the way it makes use of people and the technology. This is currently done in traditional systems engineering.

Functional STP. This STP is also employed in traditional systems engineering. Thus, a functional analysis would be performed showing what functions the RAFBADS performs (in terms of information flows, vectoring of RAF aircraft, etc.) so as to gain and maintain control of the air.

Big picture STP. The big picture STP described below covers:

1. the context or environment of the RAFBADS,

2. the assumptions in the design of the RAFBADS, and

3. its relationships with its adjacent systems.

Context. The context consists of two containing systems as follows:

- The situational context, a war in which the country is facing an enemy intent in invading and conquering it. The RAFBADS is the first line of defence responding to enemy attempts to open a breech in the defences.

- The organizational context, the RAF with its traditions, procedures and organizational structure.

Assumptions. The assumptions upon which the RAFBADS are based are as follows:

- The resources needed to operate the RAFBADS, namely, pilots, fuel, aircraft and (mains generated) electrical power are outside the boundary of the RAFBADS and provided to it.

- Weather is an important factor. The state of technology is such that enemy attacks are to be expected only in good weather ${ }^{4}$. This assumption, if validated, allows the down

\footnotetext{
${ }^{4}$ The term needs a more precise definition with respect to visibility, cloud, etc.
} 
time due to bad weather to be applied to maintaining the system (non-critical preventive maintenance, pilot rest time, etc.).

- The rescue of downed pilots is outside the system. However, this was changed in 1941 after having learned the need to bring the function inside the system (Bungay, 2000) page 68).

Adjacent systems. Adjacent systems perform the other functions of fighting a war. The immediate adjacent (tightly coupled) systems provide the inputs to the system, namely fuel, ordnance, pilots and aircraft to the RAFBADS. Identifying these systems outside the boundary of the RAFBADS pointed out a need for a meta-system in which the RAFBADS and the systems producing the resources for the RAFBADS are subsystems of the metasystem. When implemented, the need for pilots, ordnance, replacement aircraft and fuel was identified and appropriate adjacent systems instituted. However, the reliance on external power seems to have been overlooked until enemy action destroyed the power lines and brought down a section of the system. Early identification of this reliance on external power might have led to a requirement for emergency standby power generators.

Other loosely coupled adjacent systems perform functions such as:

- Prevention of attacks by destroying resources needed by the Luftwaffe to mount attacks.

- Damaging the enemy's ability to wage war.

- Contributing to ending the war in England's favour.

Structural STP. The structural STP in this case is very much a physical view. Information about the location of the enemy is generated by the audio and visual observers and Radar sites and sent to Fighter Command HQ. HQ sends the information on to the Groups and finally it is disseminated to the appropriate airfields. Information about the state of readiness of the airfields and squadrons and the results of air engagements are sent back from the airfields to Fighter Command HQ.

Generic STP. From the generic STP the RAFBADS is operating in a siege situation. Historically, sieges have ended either when the enemy gives up and departs, or when the enemy breaks through the defences and slaughters the defenders. Thus the purpose of the RAFBADS is to prevent the enemy attacks from succeeding until the enemy decides to go away or is defeated by one of the loosely coupled adjacent systems mentioned in the Big Picture STP.

In traditional city sieges, the pivotal situation is when the enemy breaks though the defences and enters the city usually through a hole in the defences. The generic STP indicates that the analogy to a hole in the defences in this situation would be the control of the air over the south coast of England by the Luftwaffe. Factors contributing to this situation would be ${ }^{5}$ :

- Loss of airfields - since aircraft cannot be launched.

- Loss of radar information - since the point of attack cannot be determined and defenders scrambled and vectored to meet them.

This information is made use of in the operational scenarios. This STP indicates that the airfields would be primary targets for destruction by the enemy by likening the situation to the need by a besieger to destroy the guns that deterred attackers from approaching too close to the city to effect and utilize a breech in the defences. This STP would also provide the insight that if the airfields are prime targets, then any physical structures adjacent to the

\footnotetext{
${ }^{5}$ Remember the war is still in the future at the time this analysis is being performed.
} 
airfield would be likely to suffer bomb damage.

Continuum STP. This STP shows the need for an ability to operate with damage, the 'failsoft' concept discussed above. This should produce requirements for the architecture of the system. The design process would use the scientific STP to postulate failure scenarios (operational STP) and corresponding requirements.

Temporal STP. The system contains both people and technology. It can be expected to get better in time. Consequently, there will be several learning curves including:

- Pilots learning tactics of air combat, and

- Ground to air communications.

This STP also:

- Illuminates the need for training and the logistics needs for ensuring availability.

- Provides insights leading to the adoption of a maintenance concept.

- Recognizes the need to make use of lessons learned from similar conflicts. At that time the only aspects of conflicts in the air which could provide some lessons learned would most likely have been (1) bombing in the Spanish Civil War ${ }^{6}$ and (2) strafing of airdromes in the First World War.

Quantitative STP. The quantitative STP relates to the big picture and to the operational and functional perspective. The big picture perspective identifies the need for quantitative information about:

- Number of RAF aircraft and pilots ready to fly.

- Number of losses on both sides.

- Number, type, location, speed and direction, of Luftwaffe aircraft approaching, or over England.

- Ratio of losses between the RAF and the Luftwaffe to provide a sense of how the battle is progressing.

- The accuracy and timeliness of the information.

The operational and functional STPs describe the response of the system to the detection of enemy aircraft heading towards the English coast. This description provides the basis for determining quantitative factors such as:

- Range of aircraft (time in the air).

- Response time to deploy fighters.

- The initial availability requirements would be seven days a week during daylight to cope with anticipated day attacks. However the degree of availability might be different for night than for day. The designers of the meta-system would have to commission an analysis to determine if the need for a night time defence could and would be met by night fighters or by anti-aircraft guns and search lights, or a combination thereof. That study would provide the information pertaining to the night time availability requirements.

The information leads to trade-off studies between candidate solutions (designs) provided by the scientific STP which determine the performance requirements for the subsystems. For example, the closeness to the coast of the initial time of detection of an enemy incursion, and the locations of the RAF airfields determines the response time to deploy the fighters from

\footnotetext{
${ }^{6}$ Zeppelin attacks as per the First World War would be very unlikely.
} 
each airfield to meet the incoming bombers.

This STP also indicates that some measure of the degree of "the holes in the defences" could be inferred by enemy if they were to have a way of measuring the number of RAF fighter aircraft responding to incursions.

Scientific STP. The generic and temporal STPs provide lessons learned from Spain and the First World War which indicates that airfields would be prime targets for bombing. As such, the scientific STP would examine the operational scenarios for airfields under attack and being repaired. This examination would provide information for the trade off which will consider the advantages and disadvantages of locating HQs close to airfields before a HQ located next to an airfield is actually bombed taking the system down for a while. This flaw in the system architecture was discovered the hard way as a result of enemy bombing.

The operational STP describes scenarios which minimize and quickly repair "holes in the defences". The scientific STP meets this need by working out ways of defending or hiding radar sites, repairing bomb damage to airports and other critical installations, providing back up power generators in the event of damage to the utility lines outside the system and ways of providing back up capability for other functions to minimize down time.

\section{Discussion}

The RAFBADS example has shown how each STP provides information about the system, and how information from one STP is used to augment information in one or more of

Table 2 Systems Thinking Perspectives Worksheet

Thinking about

\begin{tabular}{|c|c|c|c|c|c|c|}
\hline \multirow{2}{*}{ STP } & 1 & 2 & 3 & 4 & 5 & 6 \\
\hline & Who? & What? & Where? & When? & Why? & How? \\
\hline Operational & & & & & & \\
\hline Functional & & & & & & \\
\hline Big picture & & & & & & \\
\hline Structural & & & & & & \\
\hline Generic & & & & & & \\
\hline Continuum & & & & & & \\
\hline Temporal & & & & & & \\
\hline Quantitative & & & & & & \\
\hline Scientific & & & & & & \\
\hline
\end{tabular}

Notes: From each perspective (row) advance across the columns posing the question to yourself or to the discussion group. Note the response either in the area of the worksheet or on a separate paper referencing the grid coordinates. If no immediate response comes to mind, skip to the next column. 
the other STPs. The example has illustrated that the STPs are interdependent, namely information gained from one STP influences, is used other STPs, or an insight may be obtained from the combination of STPs. This illustrates that the approach is holistic since the definition of each STP and the corresponding allocation of content to each of the STP is for the convenience of the user, and is not a mirror of the real world ${ }^{7}$. However, the approach and the STPs have proved useful and discussed above, and as the following insights show. Insights from the STPs include:

- They provide a way to begin to meet the recognized need of actually applying systems thinking.

- The notion that "systems must have a purpose" is a scientific perspective (hypothesis) applicable to systems in the higher layers of the HKM Framework.

- The operational STP depicts who does something, while the functional STP depicts what (and sometimes how) is being done. The operational and functional STPs contain built-in feedback loops. Thus by definition their use will require the application of non-linear thinking and consideration of relationships in contrast to the 'cause and effect' approach currently used in linear thinking."System dynamics is the study of processes through the use of systems and how they can be modeled, explored and explained" (Clark, 1998). A process consists of activities or functions. Hence in systems thinking, systems dynamics is a tool with which to perform functional and operational analyses.

- Soft Systems Methodology (SSM) (Checkland and Scholes, 1990) came out of Operations Research and incorporates some systems thinking. Its "root definition" describes the purpose of the system while the CATWOE template seems to align as shown in Table $3^{8}$. The grouping of elements is a

Table 3 Apparent relationship between SSM's CATWOE and the STPS

\begin{tabular}{|l|c|}
\hline CATWOE & $\begin{array}{c}\text { Systems Thinking } \\
\text { Perspective }\end{array}$ \\
\hline Client/customer & Big picture \\
\hline Actor & Operational \\
\hline Transformation & $\begin{array}{c}\text { Functional and } \\
\text { Quantitative }\end{array}$ \\
\hline Weltanschauung & Big Picture \\
\hline
\end{tabular}
process of functional allocation, namely design. Thus SSM is not "systems thinking" per-se; rather it is a useful tool which incorporates some systems thinking concepts. It should be given recognition for introducing an early application of systems thinking into systems engineering. In addition, from the generic perspective, the meaning of "Weltanschauung" seems to be the same as that of "paradigm" (Kuhn, 1970; Churchman, 1979) page 105).

- The quantitative STP leads to the question "how will we know the system solves the problem or meets our needs?" This generates both the performance requirements and the acceptance criteria for the system should bring T\&E into the SDLC at the beginning of the project.

- The operational and functional STPs describe what is being done, the quantitative STP describes both how well it needs to be done (requirements) before the system is implements, and then how well it is done (measures of performance) when the system is tested. Thus the STPS clarify the relationship between functions and requirements. For any specific system, the enterprise is its containing system as shown in the big picture STPs in Figure 1 and Figure 3. The big picture STP, by definition provides

\footnotetext{
${ }^{7}$ Just like any other system representation.

${ }^{8}$ The boundaries do not align directly because the decomposition of systems thinking is different.
} 
knowledge of the immediate adjacent (tightly coupled) systems. Identifying these adjacent systems outside the boundary of the system under consideration in this manner points out a need for some meta-system which will treat the system under consideration and the adjacent systems producing its inputs, and the adjacent systems accepting its outputs as its subsystems as discussed in the RAFBADS example. This meta-system could also be considered as the system of systems or the family of systems in which the specific system fits.

- Benchmarking is an example of the application of the generic STP.

- Other insights from the generic STP include:

○ Systems engineering is demonstrating the wicked problem scenarios (Rittel and Webber, 1973) inherent to emerging disciplines.

- Reinforcement of the recognition that both reductionism and systems thinking need to be used to provide different information necessary (inward and outward views) to understand the nature of the problem/system.

$\circ$ Pattern matching is the application of the generic STP.

- As discussed above, the concept of lessons learned comes from both the generic and temporal STPs.

- An aspect of the continuum STP can be illustrated from Maslow's observation of human behaviour which was "I suppose it is tempting, if the only tool you have is a hammer, to treat everything as if it were a nail" (Maslow, 1966) pages 15 and 16). Applying the continuum STP a systems engineer would note that:

1. nails are the solution to one class of problems,

2. nails might be a solution to other classes of problems (although not necessarily optimal), and

3. the rest of the classes of problems should be monitored while the systems engineer gets the correct tool to tackle that class of problem.

- The continuum STP also makes note that there may be times when the need to do something about the problem is so urgent, and in the absence of any other alternative, that nails are the only available solution.

As an example, if you need to cut a plank in half, it can be done by hammering a series of nails along the line to be cut, extracting the nails and then scoring the line of holes until the plank breaks. However, it will be better to get and use a saw to do the job unless you need that plank cut before someone can get the saw.

- Another point that emerges from the temporal STP is that the current paradigm in any discipline is a step in the staircase of history and practitioners need to be open to considering and accepting changes that improve the discipline.

- The Theory of Inventive Problem Solving (TRIZ) ${ }^{9}$ seems to have come from a combination of the generic and the temporal STPs. Genrich Altshuller examined hundreds of patents (generic) granted over a period of time (temporal) and classified them by the process used to create the item that was the subject of the patent. TRIZ is a problem solving process that has evolved over the last 50 years whose underlying concept is "Somebody someplace has already solved this problem (or one very similar to it.) Creativity is now finding that solution and adapting it to this particular problem" (Barry, et al., 2007), namely incorporating lessons learned from other

\footnotetext{
${ }^{9}$ Altshuller named it Teoriya Resheniya Izobreatatelskikh Zadatch which has been translated into English as the Theory of Solving Inventive Problems or TRIZ to maintain the sound of the acronym.
} 
people into the problem solving process by definition.

- The complexity perceived in implementing network centric systems in Defence may be bypassed by applying the continuum STP to redefine the problem from "how best to use technical capability" to "how best to use an integrated information environment" and considering it from various STPs posing the Kipling "who, what, where, when, why and how" questions. Redefining the problem in this manner, one finds that a similar problem has already been solved more than 50 years ago in the RAFBADS discussed above as the following description shows.

"Work on the system began in 1937 and it was still being refined in 1940... ... It was a remarkable creation. It brilliantly solved the problems of dealing with massive amounts of data from a wide range of sources in a very short time and using it to exercise control over the fighting. It was a system for managing chaos. Its intelligence gathering capability extended to the period after an engagement, enabling Dowding and his generals to blow away the fog of war very quickly. It possessed a Defence Teleprinter Network (DTN) connecting all RAF stations and Headquarters. After raids, the DTN was full of information gathered from returning pilots in de-briefs as well as from those who stayed on the ground. As a result loss details, combat reports, ground damage reports, casualties, aircraft and equipment requirements were easily disseminated throughout the whole system'. Its fundamental excellence and its ultimate success in practice can be attributed to a number of features.

Firstly, its operational structure was simple and roles were very clear. Everyone knew what they had to do. It was not parsimonious with information: plot data was shared widely and passed simultaneously to several levels at once. Bentley Priory gave out information simultaneously to groups and sectors and sectors could plug into local Observer Groups once they knew something was up in their area. It was in effect an analogue intranet. Whilst it was used to transmit orders down the chain of command, it was also designed to allow anybody in the system to find out what they wanted when they wanted it from anybody else. It was a network organization based on telephone lines rather than e-mail" (Bungay, 2000) page 64).

- Understanding that some systems behaviour (functional and operational STPs) may be cyclic and may take anything from seconds to thousands of years to complete a single cycle (temporal STP) and other systems exhibit behaviour that often follows the same pattern (generic STP) from birth through, growth, stagnation and decay to death (temporal STP).

- The United States Department of Defense Architecture Framework (DoDAF, 2004) in general, only seems to provide a static view. Table 4 provides an approximation of the

Table 4 Mapping between DODAF and STPs

\begin{tabular}{|c|c|c|c|c|}
\hline & All View & Operational View & System View & Technical View \\
\hline Operational & $\mathrm{X}$ & $\mathrm{X}$ & - & $\mathrm{X}$ \\
\hline Functional & $\mathrm{X}$ & $\mathrm{X}$ & $\mathrm{X}$ & $\mathrm{X}$ \\
\hline Big picture & $\mathrm{X}$ & - & - & $\mathrm{X}$ \\
\hline Structural & $\mathrm{X}$ & - & - & $\mathrm{X}$ \\
\hline Generic & - & - & - & - \\
\hline Continuum & - & - & - & - \\
\hline Temporal & - & - & - & - \\
\hline Quantitative & - & - & - & - \\
\hline Scientific & - & - & & \\
\hline
\end{tabular}


mapping between the STPs and DODAF. The exact mapping is likely to depend on how the DODAF is employed and some of the relationships may be more significant than others. As might be expected from a framework, the DODAF mainly covers static aspects that describe the "what" of the system; what the operations, functions, worldview and structure of the system are. These aspects map into the operational, functional, big picture and structural STPs. The remaining STPs - generic, continuum, temporal, quantitative and scientific, serve a different purpose.

\section{Speculations and avenues for further research}

Completeness of the STP approach. When thinking about problems it is advisable to ask the question, "Have I covered all aspects of the problem". Applying the STPs to the STPs itself, one might rephrase the question as "have I looked at the problem from every possible perspective?" The point then becomes to determine whether the STPs as defined in this paper represent a complete set of ways of thinking about a problem. In pursuit of considering all lines of enquiry, possibly a good place to start would be the "six honest serving-men" (Kipling, 1912) questions mentioned above. Using them as the basis, the basic lines of enquiry of thinking about a problem could be framed as follows:

- What is the problem?

- How should it be solved?

- Why do you want to solve it?

- Where and when do you want to solve it?

- Who is needed to solve it and who has solved a similar problem?

The STPs generally cover the "what" and the "how". The "what?" is represented by the operational, functional, big picture and structural STPs, whereas the "how?" is addressed by the generic, continuum, temporal, quantitative and scientific STPs. The "why?" does not seem to be generally addressed, and would seem a very important additional consideration for issues such as:

- Is the problem the right one to solve?

- Is the problem being solved at the right level?

- Is there a danger of addressing symptoms of a problem rather than the root cause?

- Might the solution merely transfer the problem elsewhere?

The "where", "when" and who "might" seem to be just expedient, but it might be argued that the choice of "when" in particular, may have a bearing on solving a problem, especially when the problem itself is changing or the available resources for solving the problem are time dependent. Equally, the "who" will have a bearing on how the problem is solved, its potential outcome and may in itself contribute to the problem!

It would seem, therefore that further examination of the STPs could be beneficial in terms of modifying them to offer a more complete set.

Can the scientific STP be generalized further? Pursuing the thought of modifying them, the first eight STPs have been identified as descriptive, but the ninth, the scientific STP is of a different nature as it prescribes the approach to be taken. From the continuum STP, the scientific method should be a point on a continuum. This thought leads to the question; if the scientific perspective is a point on a continuum, what is the nature of that continuum? 


\section{Summary}

This has been a paper on thinking about thinking. This paper proposed a set of STPs for applying systems thinking in systems engineering based on a modification of the streams of system thinking (Richmond, 1993). The paper contained an example of an attempt to align systems thinking with systems engineering by applying the STPs to the RAFBADS. The alignment seems to have been successful since it showed that not only did the STPs provide a way to represent the system, they also picked up two potentially fatal flaws in the system (the co-siting of the sector HQs with the airfields (with subsequent collateral damage to the HQ when the airfield was predictably bombed) and the loss of external power bringing down the system). The paper then discussed some observations and insights on the state of systems engineering from the perspective of the STPs providing a view of how current apparently unrelated aspects of systems engineering fit together. Finally, the paper speculated on the nature of future follow-up research.

\section{Conclusions}

When systems thinking is applied in the manner described in this paper, it can be seen that the lack of publications on the application of systems thinking is a characteristic of a paradigm change. Since, in the past it has taken years for concepts to move from articulation to adoption. For example, "In 1832, Charles Babbage, inventor of one of the earliest forms of the mathematical computer, published a treatise advocating a scientific approach to organization and management and emphasizing the importance of planning and an appropriate division of labour. However, it was not until the early twentieth century that these ideas and developments were synthesized in a comprehensive theory of organization and management" (Morgan, 1997) page 17), the application of systems thinking proposed in this paper seems to provide (Morgan, 1997)'s competitive advantage over those using current methods by providing information and insights that would not necessarily be made when the nature of the problem is being conceptualized. However, an application of the continuum STP to the STPs themselves indicate that there may be other perspectives that have been overlooked in this research or the STPs themselves may need to be redefined; consequently while being a promising start, further research remains to determine if there is an optimal set of STPs and their relative importance.

The approach used the scientific perspective to develop and test a set of STPs. Using as a test case the RAFBADS, the example shows that the approach has promise, and the alignment of the views of a system with the STPs, as described in this paper has the potential to significantly improve systems engineering. It will do this by observing and documenting systems from the STPs thus aligning systems thinking with systems engineering. Moreover, the concept already seems to be providing a view of how current apparently unrelated aspects of systems engineering fit together. However these STPS are but a stepping stone, further research is needed.

\section{Author's biographies}

Prof Kasser has been a practicing systems engineer for 35+ years and an academic for about 10 years. He is an INCOSE Fellow, the author of "A Framework for Understanding Systems Engineering" and "Applying Total Quality Management to Systems Engineering" and many INCOSE symposia papers. He is a recipient of NASA's Manned Space Flight Awareness Award (Silver Snoopy) for quality and technical excellence for performing and directing systems engineering and other awards. 
He holds a Doctor of Science in Engineering Management from The George Washington University, and is a Certified Manager. He has also served as President of INCOSE Australia and Region VI Representative to the INCOSE Member Board.

$\mathrm{He}$ is a principal at the Right Requirement Ltd. He gave up his positions as a Deputy Director and DSTO Associate Research Professor at the Systems Engineering and Evaluation Centre at the University of South Australia in early 2007 to move back to the UK to develop the world's first immersion course in systems engineering as a Leverhulme Visiting Professor at Cranfield University.

Tim Mackley is a Senior Lecturer in Systems Engineering at Cranfield University. Tim studied at Imperial College for his physics degree and also has a diploma in Advanced Systems Engineering. Previously he has had a successful career in industry, during which he worked as a systems manager and engineer on a wide variety of projects, from concept through full-scale development and delivery. He now concentrates on research into Systems Engineering and lectures on various postgraduate courses and short courses for industry.

\section{References}

Ackoff, R. L., "The Future of Operational Research is Past," Journal of the Operational Research Society, Volume 30, 1979, in Critical Systems Thinking Directed Readings, R. L. Flood and M. C. Jackson (Editors), 1991.

Barry, K., Domb, E. and Slocum, M. S., TRIZ - What Is TRIZ?, 2007, http://www.trizjournal.com/archives/what_is_triz/, last accessed 31 October 2007

Bungay, S., The Most Dangerous Enemy, Aurum Press, London, England, 2000.

Checkland, P. and Scholes, J., Soft Systems Methodology in Action, John Wiley \& Sons, 1990.

Churchman, C. W., The Systems Approach and its Enemies, Basic Books, Inc., New York, 1979.

Clark, R., System Dynamics and Modeling, Operations Research Society of America, 1998.

DoDAF, DoD Architecture Framework Version 1.0, 9 February 2004, 2004.

Flood, R. L. and Jackson, M. C., Critical Systems Thinking Directed Readings, John Wiley \& Sons, Chichester, 1991.

Hately, D. J. and Pirbhai, I. A., Strategies for Real-time systems Specification, Dorset House Publishing, New York, NY, 1987.

Hitchins, D. K., Putting Systems to Work, John Wiley \& Sons, Chichester, England, 1992.

Hitchins, D. K., "Systems Engineering...In Search of the Elusive Optimum", proceedings of Fourth Annual Symposium of the INCOSE-UK, 1998.

Kasser, J. E., Applying Total Quality Management to Systems Engineering, Artech House, Boston, 1995.

Kasser, J. E., "Writing Requirements for Flexible Systems", proceedings of INCOSE-UK Spring Symposium, 2001.

Kasser, J. E., "Configuration Management: The silver bullet for cost and schedule control", proceedings of The IEEE International Engineering Management Conference (IEMC 2002), Cambridge, UK, 2002.

Kasser, J. E., "A Proposed Paper Template for improving the Quality of Practitioner Written Papers at Conferences and Symposia", proceedings of The 16th International Symposium of the International Council on Systems Engineering (INCOSE), Orlando, FL., 2006.

Kasser, J. E., "The Hitchins-Kasser-Massie (HKM) Framework for Systems Engineering", proceedings of the 17th International Symposium of the INCOSE, San Diego, CA., 
2007a.

Kasser, J. E., "Luz: from Light to Darkness: Lessons learned from the Solar System", proceedings of INCOSE Asia-Pacific Systems Engineering Conference, Adelaide, Australia, 2007b.

Kasser, J. E., "A Proposed Framework for a Systems Engineering Discipline", proceedings of The Conference on Systems Engineering Research, Hoboken, NJ, 2007c.

Khisty, C. J. and Mohammadi, J., Fundamentals of Systems Engineering with economics, probability and statistics, Prentice-Hall Inc., Upper Saddle River, NJ, 2001.

Kipling, J. R., "The Elephant's Child," in The Just So Stories, The Country Life Press, Garden City, NY, 1912.

Kuhn, T. S., The Structure of Scientific Revolutions, The University of Chicago Press, 1970.

Maslow, A. H., The Psychology of Science, Harper and Row, 1966.

Maslow, A. H., Motivation and Personality, Harper \& Row, 1970.

McGregor, D., The Human Side of Enterprise, McGraw-Hill, 1960.

Morgan, G., Images of Organisation, SAGE Publications, Thousand Oaks, CA, 1997.

Moubray, J., Reliability-centered Maintenance, Elsevier Butterworth-Heinemann, Oxford, 2005.

Richmond, B., "Systems thinking: critical thinking skills for the 1990s and beyond", System Dynamics Review, Vol. 9 (1993), no. 2, 113-133.

Rittel, H. W. and Webber, M. M., "Dilemmas in a General Theory of Planning", Policy Sciences, Vol. 4 (1973), 155-169.

Wymore, A. W., Model-Based Systems Engineering, CRC Press, Boca Raton, 1993. 